\title{
JOSE ANGEL VALENTE O EL HOMBRE HABITADO \\ "Al dios del lugar" a la luz de \\ "Variaciones sobre el pájaro y la red". Una propuesta de lectura
}

\author{
por \\ EVA VALCARCEL
}

\begin{abstract}
Al dios del lugar constituye la última entrega poética de J. A. Valente, quien promete ahora, en la cubierta de su última colección de ensayos, Variaciones sobre el pájaro y la red, un nuevo libro de poemas que se publicará en la próxima primavera, y que se titulará No amanece el cantor. Valente es tan lúcido poeta como ensayista, y la publicación de sus Variaciones... nos ofrece la oportunidad de contrastar y confirmar, una vez más, sus teorizaciones estéticas con sus logros poéticos ${ }^{1}$.

Al dios del lugar, tal como se puede sospechar de la interpretación de su título, es una obra que concibe el lenguaje y su dimensión formal poética como un espacio propicio para la manifestación del dios. El libro es ofrecido por el poeta en señal de reconocimiento a ese dios del lugar. La colección consta de cuarenta y dos poemas nombrados por la palabra inicial de su
\end{abstract}

\footnotetext{
' Variaciones sobre el pájaro y la red, Tusquets, 1991, se publica precedido de La piedra y el centro, colección de ensayos que Valente había publicado por primera vez en 1982.
}

"CUADERNOS DE ESTUDIOS GALLEGOS", Tomo XL, Fascículo 105, Santiago 1992. 
primer verso, transcrita en caracteres mayúsculos, signo caracterizador éste que nosotros utilizaremos aquí para nombrar las diferentes unidades poemáticas.

En este libro o fragmento de escritura, Valente no cesa en su indagación, con la coherencia que caracteriza todos sus trabajos estéticos, sobre la relación o paralelismo que existe entre la experiencia del místico y la del creador. Estados que se hacen uno para Valente, puesto que los dos, místico y poeta, -queda claro que ambas denominaciones no se excluyen sino que se complementan- deben situarse ante el fenómeno o la realidad del lenguaje con una idéntica mirada: los dos han de trazar con el lenguaje los signos de una experiencia que los sobrepasa ${ }^{2}$. Una experiencia extrema del cuerpo y también del lenguaje. Ambos, cuerpo y lenguaje, tienden a disolverse en esa experiencia del límite y en esa disolución encuentran su radical significación.

Ante el vacío previo a toda manifestación del dios, el creador, y el místico, han de empujar firmemente y con certeza al lenguaje hasta el punto en el que éste se descondiciona de sí de tal manera que silencio y palabra ${ }^{3}$ se unifican, de la misma manera que criatura y dios se hacen uno cuando han conseguido negar los límites, perdiendo así la identidad de sí, disolviéndose en lo Uno, el que no necesita de sí ni de otro para reconocerse ${ }^{4}$.

Una vez apuntado el carácter totalizador de la escritura, nos proponemos elaborar unas notas que expliquen el sentido místico y eucarístico de los textos para proponer una lectura que aclare las claves simbólicas y filosóficas que en ellos están presentes.

Hemos titulado este artículo como el hombre habitado ${ }^{5}$ para hacer

2 Vid. Valente, La piedra y el centro, Madrid, Taurus, 1982, 1르. ed., p. 73:

El místico tiene que situarse en el lenguaje, señalarnos desde el lenguaje y con el lenguaje una experiencia que el lenguaje no puede contener.

${ }^{3}$ Cfr. Valente, La piedra y el centro, Ensayo sobre Miguel de Molinos, p. 74:

Porque el silencio no es Dios ni la palabra es Dios (...) Dios está oculto entre ambos.

${ }^{4}$ Vid. Valente, La piedra..., p. 76:

Abandono del carácter utilitario que el lenguaje tiene en el discursus viene impuesto por la abolición de éste, por el tránsito del proceso discursivo a la visión intelectiva, al entender propiamente noético que en el caso del místico es un saber del no saber.

${ }^{5} \mathrm{Cfr}$. Valente, Ibidem:

Negación de los límites, irresistible salida. Salida de los propios límites, de sí mismo, y en ese proceso de salida se lleva a cabo la destrucción o deshacimiento, según San Juan, de la identidad del sí mismo (sólo pensable como oposición a otro) por unión con el non aliud, el que no es otro con respecto de nadie.

"CUADERNOS DE ESTUDIOS GALLEGOS", Tomo XL, Fascículo 105, Santiago 1992. 
resaltar el momento axial de la experiencia mística, el éxtasis, en el que el ser de dios y el ser del hombre son borrados de sus límites y se funden -con el Amado en San Juan, con el dios innombrable en Valente- y participan de la experiencia de lo Uno ${ }^{6}$.

\section{EL VINO Y LAS CENIZAS}

El poema que abre el libro se inicia con el siguiente verso: $E$ l vino tenía el vago color de las cenizas. Se inscriben en él dos coincidentes que aúnan principio y fin de un proceso de entrega, de un proceso eucarístico. Este poema contempla, para la creación poética, un discurso similar al de la entrega eucarística, en el cual una materia, se realiza y adquiere su forma, al ser habitada por el Dios; en este caso se trata de un dios conocido, lo cual ya no es posible en el proceso de escritura, en el cual, el hombre es poseído por un dios incógnito. Esta aceptación aparece destacada por Valente en la página que precede a su poemario. Allí, con una cita, quiso escribir significativamente He has a god in him though I do not know wich god ${ }^{7}$.

Nos dice el poeta que el vino tenía un color indefinido como la indefinida ceniza; lo obvio sería el color de la sangre pero no parecía la sangre, sino que era la misma sangre, o la ceniza o residuo del dios en el cáliz sagrado:

El insidioso fondo de la copa

esconde a un dios incógnito

Me diste

a beber sangre

en esta noche.

Fondo del dios bebido hasta las heces.

El vino sagrado se identifica con un valor residual y precioso; vino es

${ }^{6}$ Yo soy cenizas, dice Abraham, Génesis 18-27.

Cfr. Variaciones..., p. 257: Palabra que renace de sus propias cenizas. Incesante memoria. Residuo o resto de lo cantable.

${ }^{7}$ La cita procede de The Cantos.

"CUADERNOS DE ESTUDIOS GALLEGOS", Tomo XL, Fascículo 105, Santiago 1992. 
ceniza, ceniza es resto del dios y es signo de su eterno retorno ${ }^{8}$. Ceniza es pura esencialidad. Es aquél elemento que permanece después de la extinción del fuego. El vino es un elemento primario y elemental, y precario y residual, puesto que posee las características de la indefinición y de la informidad: vago color de las cenizas; la indefinición esencial y original aparece ahí, lo informe está en la esencia misma del sustantivo cenizas y en la significación plena del adjetivo vago. Las cenizas nos acercan al origen y a la transformación final del hombre en polvo. Recordemos la frase ritual de la liturgia, eres polvo y te convertirás en polvo. Tradicionalmente las culturas han unido el símbolo del vino a la sangre porque su color y la agitación o el efecto de vitalidad que produce, ayudan a esa identificación. Ese efecto excitante de la ebriedad, don que el vino proporciona, posibilita que las tradiciones semíticas lo asocien con el conocimiento o la iniciación a ciertos misterios, ya que, sus efectos desanudan la razón.

San Juan de la Cruz propuso, a este respecto, tres posibilidades de penetración de la influencia del vino; así diferencia entre la vía del conocimiento intelectual, en cuyo caso el vino proporcionaría sabiduría de Dios; la vía de la voluntad, mediante la cual se identificaría el vino con el amor de Dios; y finalmente, por medio de la memoria, el vino y su experiencia significaría y proporcionaría al ser del hombre, la delicia del Encuentro.

Este vino, es el mismo vino que Jesús en la Cena identifica con su sangre y como la sangre símbolo de la Alianza ${ }^{9}$. Esa proximidad a la corporeidad divina es la que, en última instancia, se recoge en este poema emblemático de Valente. Ese vino es fuego y, unido al principio húmedo, ejerce en el alma efectos maravillosos propicios a la manifestación del dios:

Se bebía con un poso de sombra

oscura, sombra, cuerpo

mojado en las arenas.

\footnotetext{
${ }^{8}$ En el Deuteronomio 32, 37, 38 se habla del vino como la bebida de los dioses, y en el Exodo 29,40 se dice que en Israel el vino tiene un lugar central en los sacrificios de culto. En el Cantar de los cantares, 2, 4 se puee leer; Introdúceme en la casa del vino. También podemos descubrir la significación de vino como cólera de los dioses, en Isaías 15, 17 y en el Apocalípsis 9, 15.

${ }^{9}$ Vid. Evangelio de S. Marcos 14, 24.
}

"CUADERNOS DE ESTUDIOS GALLEGOS", Tomo XL, Fascículo 105, Santiago 1992. 
La humedad precede a la forma, y la noche, territorio de la salida, precede a la luz, al fulgor. Este proceso es insistentemente reelaborado por el poeta desde el inicio de su andadura poética ${ }^{10}$.

En este caso se trata de un vino preñado de sombras húmedas. Calor, fuego y humedad constituyen el vino, el cual nos aproxima al dios que se manifiesta en ese momento de ebriedad, ese dios ofrece su cuerpo y su sangre en una copa. Por medio de la absorción del contenido de esa copa, el dios habitará entre los hombres:

\section{El insidioso fondo de la copa}

esconde a un dios incógnito.

El verso que nos acercó a esta reflexión constaba de dos elementos simbólicos que lo abrían y cerraban como límites de un proceso intelectual, también manifiesto en la escritura. Esos dos elementos aparecían en la escritura morfológicamente marcados por la fuerza del singular; así encuadraban el verso; EL VINO (tenía el vago color de) LA CENIZA. El espacio central que ocupan el poema y el verso, los dos poseen las cualidades de primero. El verso aparece separado del cuerpo central del poema, como origen, prólogo y residuo o epílogo a la vez, en un aislamiento premeditado del corpus completo del texto. La Unicidad se deriva de esa condición paradójica.

El poema que se inicia con el verbo QUEDAR desarrolla el mismo proceso intelectual. Este poema -que lleva una indicación esclarecedora a su término: (Fénix)- nos remite al concepto de ceniza como residuo o raíz, es decir, germen de donde surgirá otra vez, e incesantemente, la vida; es la ceniza que facilitará el nuevo retorno. Ella es el residuo del cuerpo del ser que, habitado, ha conseguido la cumbre de la creación y arde con ella. El cuerpo es aquí sólo un envoltorio, un instrumento del dios, ese cuerpo es transitorio y tiene sentido únicamente porque el dios se manifiesta a través

\footnotetext{
${ }^{10} \mathrm{Cfr}$. Valente, La piedra y el centro, p. 15:

La forma se cumple en el descondicionamiento radical de la palabra. La experiencia de la escritura es, en realidad, la experiencia de ese descondicionamiento y en ella ha de operarse ya la disolución de toda referencia o de toda predeterminación. Para la teorización poética de Valente, desde sus inicios poéticos hasta los últimos libros, véase Eva Valcárcel, El Fulgor o la palabra encarnada, Barcelona, PPU ed. 1989.
}

"CUADERNOS DE ESTUDIOS GALLEGOS", Tomo XL, Fascículo 105, Santiago 1992. 
de él. Se incendia para cerrar el proceso de la noche creadora, cuando llega la luz, el día, su razón de ser desaparece y se quema ${ }^{11}$.

Este es el desarrollo de un proceso de consecución o logro de la creación. En él, aire y fuego y materia corpórea se funden para coronar la noche con un fulgor que procede de su disolución en cenizas; consiguen el día desde su principio: la noche ${ }^{12}$. La noche en la poesía de Valente aparece nombrada como la cima de la madrugada, el punto más alto, el antedía, espacio en el que el cuerpo se yergue en sacrificio. El hombre de la salida de la noche oscura es una vez que la unión y la iluminación se cumplen, el hombre del continuo retorno:

\section{QUEDAR \\ en lo que queda \\ después del fuego, \\ residuo, sola \\ raíz de lo cantable.}

(Fénix)

Pero no todo termina al final de ese proceso, puesto que en ese elemento residual e informe no termina definitivamente la trayectoria de un cuerpo. Nos es bastante próximo el mito del ave que renace de sus cenizas, ése es en última instancia, el destino del hombre. El continuo arder y renacer es un punto axial en el proceso creador de Valente. Cuando el poeta es habitado por un dios y bajo los efectos de esa posesión, se origina de él una forma. Ese instante mágico y perfecto termina siempre con un arder en el aire para

\footnotetext{
$"$ Vid. Valente, Variaciones..., La memoria del fuego, p. 256.

La llama es la forma en que se manifiesta la palabra que visita al justo en la plenitud de la oración, según una imagen frecuente en la tradición de los hassidim. Y, por supuesto, la Torah celeste está escrita en letra de fuego.

${ }^{12}$ Vid. Valente, Variaciones..., Sobre el lenguaje de los místicos: convergencia y transmisión, pp. 166:

El vaciado de la interioridad del yo, que hace posible su ocupación total por lo divino, tiene en místicas tan diferenciadas como las de Eckhart y Hallâj (s. IX-X) mecanismos y formas de expresión muy próximas. En definitiva, el salirse el alma de sí y el salirse el Dios de sí para identificarse en lo que Eckhart llama la unidad simple es el mismo proceso espiritual en que se funda o se cumple la famosa proposición identificativa Ana'l Hagg (yo es Dios o la Verdad) que iba a llevar al místico musulmán al martirio.
}

"CUADERNOS DE ESTUDIOS GALLEGOS", Tomo XL, Fascículo 105, Santiago 1992. 
renacer más tarde, a través del mismo proceso reiterado ${ }^{13}$.

En el Cristianismo, experiencia religiosa que marca el imaginismo poético de Valente, se coloca a los muertos en la tierra matriz (pulvis) sobre un recubrimiento de ceniza en forma de cruz para simbolizar así, e invocar también, la primigenia alternancia universal eternamente repetida; muerte de la que se sale a la vida y desde la que se tiende inexorablemente a la muerte para reiniciar el ciclo y cerrarlo infinitas veces.

El mito del eterno retorno está presente pues en la escritura que analizamos. El primer verso de este poema que nos ha servido de eje para nuestra lectura, asocia la vida y la precariedad vital. Los dos conceptos o estados, aunque antagónicos en principio, no son tan lejanos. La sangre, o el vino, y la ceniza forman parte de un proceso que se sucede a sí mismo en la escritura, como veremos en otros poemas.

\section{LA NECESIDAD DE LA PRECARIEDAD}

En el acto de la creación, para que el cuerpo sea habitado por el dios se necesita un vacío ${ }^{14}$ silencioso que precederá a la manifestación de la forma. Cuando el creador es habitado o poseído por un dios, su identidad desaparece para permitir que se pose el dios ${ }^{15}$ :

\section{BORRARSE.}

${ }^{13}$ Vid. Valente, Variaciones..., La memoria del fuego, p. 257:

Palabra que renace de sus propias cenizas para volver a arder. Inacesante memoria, residuo o resto cantable: "Singbarer Rest", en expresión de Paul Celan. Pues, en definitiva, todo libro debe arder, quedar quemado, dejar sólo un residuo de fuego.

${ }^{14}$ Vid. Valente, Variaciones..., La memoria del fuego, p. 253-254:

El desierto es bastante más que una práctica del silencio y de la escuha (...) La apertura de toda escritura. Estado, pues, de disponibilidad y de receptividad máximas caracterizado por la tensión entre ausencia e inminencia (...) Ausencia e inminencia del Nombre en el no lugar donde se inicia la revelación, en el desierto, en el exilio (...) único espacio real en que esa palabra encuentra manifestación.

${ }^{15}$ Las palabras del Maestro Eckhart son: Donde termina la criatura empieza el ser de Dios. Todo lo que Dios te pide con la mayor premura es que salgas de tí mismo, entanto que tu eres criatura y que dejes a Dios ser Dios en ti. Sal totalmente de ti por amor de Dios, y Dios saldrá totalmente de sí por amor de ti. Y lo que después de ambas salidas queda en la unidad simple. Esta cita está tomada de Traités et sermons, París, Aubier, p. 42, y es citado por Valente, en La piedra y el centro, p. 77.

"CUADERNOS DE ESTUDIOS GALLEGOS", Tomo XL, Fascículo 105, Santiago 1992. 
se posa el dios.

Sólo en la ausencia de todo signo

En un estado de pureza absoluta, diáfono y elemental, el dios se posa. En la poética de Valente, con frecuencia se reiteran estas ideas: el hueco ${ }^{16}$ precede a la forma, el silencio precede y es necesario para el nacimiento de la palabra.

Este brevísimo poema nos recuerda, una vez más que el dios de la palabra exige una absorción y una dedicación única, no puede, por tanto, el creador hacer otra cosa distinta que no sea dejar de existir ${ }^{17}$ como forma autónoma, porque allí, y sólo allí donde termina la criatura, el dios comienza. El ser no ha de hacer, solo dejarse invadir, estar, estarse, no hacer. Lograr un inmenso vacío contemplativo y conseguir la permanencia en él, vaciarse, conseguir anular la voluntad y la querencia, ser sin conciencia, sin intención ${ }^{18}$. Esto es:

ESTAR.

No hacer.

En el espacio entero del estar

estar, estarse, irse

sin ir

a nada

A nadie.

A nada.

${ }^{16} \mathrm{Cfr}$. Valente, Al dios del lugar, p. 17:

FORMO

de tierra y de saliva un hueco, el único

que pudo al cabo contener la luz. (Materia).

${ }^{17}$ Cfr. Cioran, E. M., Aveux et Anathèmes, París, Arcades Gallimard, 1987, p. 10:

Le nèant pour le boudhisme (à vrai dire pour L'Orient en général) ne comporte pas la signification quelque peu sinistre que nous lui atribuons. Il se confond avec una experience limite de la lumière, ou, si on veut, avec un état d'eternelle absence limineuse, de vide rayonnant: c'est l'être qui a triomphé de toutes ses propietés ou plutôt un non-être suprêmement positif qui dispense un bonheur sans matière, sans substrat, sans aucun appui dans quelque monde que ce soit.

${ }^{18} \mathrm{Cfr}$. Valente, La piedra y el centro, Ensayo sobre Miguel de Molinos, p. 79:

La pobreza es el otro nombre de la vacuidad o del vacio o de la nada que ha de operar en su interior el alma para hacerse lugar de la iluminación. Como la salida prefigura la iluminación, sólo la pobreza prefigura la salida y la constituye.

"CUADERNOS DE ESTUDIOS GALLEGOS", Tomo XL, Fascículo 105, Santiago 1992. 
El poema que se inicia con la secuenciaEL SOL se continúa la indagación en el proceso posterior a la desposesión del yo, después de la cual, la luz divina, esto es, la gracia, se instalará en el cuerpo matérico del poeta, instrumento del dios, el poeta será el enviado, del dios, el ángel que caerá sobre las tinieblas informes, tomará su materia y pronunciará el Verbo en el límite de la noche, y en el borde mismo de la luz ${ }^{19}$ :

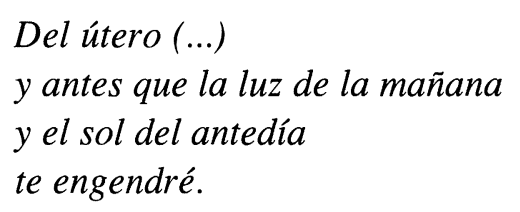

El poeta, el ángel enviado del dios, creará en un tiempo sin tiempo, antes del origen, el Verbo que se hará carne o Palabra. Ese Verbo se consigue en un despertar que pertenece tanto a la noche como al alba, ese despertar es en sí mismo el límite, la frontera, el filo de lo indistinto.

El sol, es en este poema el símbolo clave, gracias a él es posible la noche y el día, estamos ante un elemento ambivalente ${ }^{20}$, estamos ante un elemento que posibilita la resurección y la inmortalidad. Sus propiedades confirman y posibilitan el eterno retorno, su ciclo es inextinguible:

El SOL inextinguible es el descenso

a la noche de todo lo creado.

\section{EPIFANIA DEL OTRO EN LA IMAGEN DE SI}

LA LUZ se derramó

en los manteles limpios de la tarde.

Este poema nos presenta unos signos muy reconocibles: la cena, el pan, el vino.

\footnotetext{
${ }^{19} \mathrm{Cfr}$. con las palabras de San Juan de la Cruz, en la Subida al Monte Carmelo, II, 24:

... aquél vacío y tiniebla y desnudez de todas las cosas o pobreza espiritual, que todo lo podemos llamar una misma cosa...

${ }^{20}$ Zaratustra dijo que la noche también es sol.

"CUADERNOS DE ESTUDIOS GALLEGOS", Tomo XL, Fascículo 105, Santiago 1992.
} 
La llegada del emisario del dios, el ángel o el doble del poeta que se convierte en ángel cuando actúa como poseído cuerpo e instrumento del dios...

El signo se manifiesta en estos primeros versos que hemos citado. La tarde, cercana a la noche ${ }^{21}$, a la hora de la salida mística del alma en busca del Amado, es el espacio del hombre habitado, el milagro es siempre nocturno; estos versos nos disponen para él. La tarde se relaciona con la cena, con resonancias litúrgicas de cuerpo místico y de última cena, esa cena la intuimos en los manteles. Estamos ante una lectura poética del pasaje de la Ultima Cena. El dios se manifiesta de esta manera conocida ${ }^{22}$, pero esta vez permanecerá entre nosotros, al igual que lo anuncia en la Ultima Cena, cuando anuncia su muerte para redimir a los hombres. En el poema la permanencia del dios se anuncia mediante la intuición de la imagen del ángel que no se explicita en el poema -aunque se hace presente en la nota a pie de poema, en la que se explica, (Angel: Segunda elegía)-pero que se intuye en la presencia de un ser intermediario entre el mundo superior y el inferior; el ángel es ese ser, sólo puede tener apariencia de hombres y su función es la de ministro de Dios:

\author{
Permaneciste en pie \\ igual a ti \\ con el mismo ademán con que llegaras, \\ el de quien debe caminar. \\ (...) \\ Bebiste, dije, el vino claro \\ de nuestra íntima pobreza \\ y ahora \\ no podías partir.
}

El vino simbólico que contiene este texto, es un vino precario, distinto del

${ }^{21}$ Cfr. Valente, Variaciones..., Sobre la lengua de los pájaros, p. 239.

El propio movimiento creador, el Ursatz, el movimiento primario, que podría ser otro aspecto o nombre de lo Unico, o del Unico o de la Unicidad, opera la abolición infinita de las formas o su reinmersión en el ciclo infinito de la formación.

${ }^{22}$ Vid. Evangelio de S. Marcos 14, 22.

"CUADERNOS DE ESTUDIOS GALLEGOS", Tomo XL, Fascículo 105, Santiago 1992. 
vino rojo, el vino fuerza, este es un símbolo de la precariedad necesaria, no significa la luminosidad o la fuerza, sino que se trata de un vino pobre, deposeído y que entra en relación directa con otro elemento simbólico del poema: el pan ${ }^{23}$. El pan en la liturgia es considerado como alimento esencial; Cristo es el pan de vida ${ }^{24}$, pero el vino es más, porque es definido como cáliz de salvación. El pan ácido de que está compuesta la hostia representa la aflicción de la privación, la preparación para la purificación y la memoria de los orígenes. Los pequeños misterios de la vida activa están asociados, en la liturgia, al pan, mientras que al vino se asocian los grandes misterios encuadrados en la vida contemplativa.

En el poema que estudiamos aparece en un principio el pan, la vida activa, antes de la llegada del ángel. Después del ángel, la escritura se vuelve sobre el vino claro, es un vino sobre el que se operará un milagro cualitativo, tal como se espera de la tradición bíblica, es un vino pobre y claro y se convertirá después del milagro en vino rojo, en sangre, en fuerza. Conocemos los milagros relatados en la Biblia, allí se nos relata como Jesús convirtió el agua en vino (milagro cualitativo) y multiplicó los panes (milagro cuantitativo). Este ejemplo nos ayuda a reafirmar la superioridad del símbolo del vino sobre el símbolo del pan, idea que es representada por Valente en el discurso de este poema, en el que, finalmente, se produce una fusión esperada entre el poeta, el ángel y el dios.

\section{LA ESPERA DEL ORACULO EN LA NOCHE}

La espera de una manifestación en la noche y la respuesta a esa llamada es el tema reiterado en el poema LA ARENA.

\section{El súbito}

relámpago de la piedra en el aire.

$Y$ nada.

El vuelo.

$Y$ nadie.

\footnotetext{
${ }^{23}$ Vid. San Juan, 6, 13-52.

${ }^{24}$ Ibidem.

"CUADERNOS DE ESTUDIOS GALLEGOS", Tomo XL, Fascículo 105, Santiago 1992.
} 
Sabemos que en la tradición cristiana, la piedra caída del cielo suele ser el instrumento de un oráculo o de un mensaje ${ }^{25}$. Se trata de las piedras que se convierten en seres vivos después de su caída.

El relámpago ${ }^{26}$ súbito nos proporciona en el poema la imagen de la iluminación fallida. Por otra parte, se trata de una manifestación celeste y lumínica, pero su carácter súbito y también inconstante la desacretida.

Con anterioridad a este mensaje fallido, el texto nos muestra un estado y un espacio en el que se reconocen los signos del anuncio o el mensaje divino:

LA ARENA tenía el color de las escamas

de un enorme pez extendido

y la luz caída sobre ella

con el secreto brillo del acero como un ala rasante.

Vacio y extensión.

La arena, el símbolo inicial posee unas características que la hacen propicia para contener un mensaje divino. La arena está formada por una innúmera cantidad de granos, su multiplicidad es blanda y adopta la forma que le es impresa. La arena se comporta como una matriz, como un molde que aloja la forma sagrada del enorme pez.

El acero está asociado a la luna, por lo tanto a la noche, también al cuchillo, y a través de él a la sangre, también al vuelo, al ala rasante del pájaro que intercambia mensajes entre el mundo superior e inferior.

El pez es símbolo del elemento agua, elemento generador de vida por su naturaleza. Es también un símbolo cristológico. La palabra griega Ichtus que significa pescado, y fue adoptada por los cristianos como un ideograma. Asimismo, el pez es un alimento del Cristo resucitado, por lo tanto, se convierte en un signo de la comida eucarística ${ }^{27}$.

\footnotetext{
${ }^{25}$ En este, proceso lo que percibe la mirada no es una visión porque el éxtasis disuelve los visibles que son tinieblas, por medio de la potente luz, el aura prodigiosa, el relámpago, el rayo de la luz.

${ }^{26}$ Vid. Evangelio de S. Lucas, 24, 42.

${ }^{27}$ Cfr. Valente, La piedra y el centro, p. 13:

La piedra es en todas las tradiciones símbolo del centro y de la totalidad, desde el omphalos del templo de Apolo hasta el quincunce de la mitología azteca. El exilio de la piedra es, en rigor, la pérdida del centro.
}

"CUADERNOS DE ESTUDIOS GALLEGOS", Tomo XL, Fascículo 105, Santiago 1992. 
La piedra ${ }^{28}$ es el otro símbolo matricial de este poema al que ya hemos hecho referencia. La piedra guarda una estrecha relación con el alma; como el hombre nace de Dios y vuelve a Dios. La piedra bruta cae del cielo y, trasmutada, se vuelve hacia él. Es por eso, por lo que el templo debe estar construído con piedra bruta y no con piedra tallada. La piedra tallada se vuelve profana porque es obra humana y desacraliza la obra de Dios. La piedra bruta es la materia pasiva que puede ser ennoblecida por la actividad divina y espiritual. Este paso de la piedra bruta a la piedra tallada, pero no por el hombre sino por Dios, simboliza el paso del alma oscura al alma iluminada por el conocimiento divino.

\section{CUERPO QUE DEVORA EL OTRO CUERPO}

El poema COMO CRISTAL nos explica un proceso de necesidad y de fusión de dos realidades, aquí nombradas como cuerpos: cuerpo voraz en otro cuerpo ${ }^{29}$.

El texto muestra un estado de posesión absoluta por parte del dios, todos los sentidos le pertenecen:

Te hiciste sierpe, noche, viscosidad, residuo

de cuanto el otro

de sí no habría

podido nunca morir bastante.

El cuerpo se adhiere para hacer presa como una ventosa, está en todas partes: No vives sin su sangre. La sangre es el vino, la fuerza del dios, el calor, la vida y todos los valores solidarios... El hombre es el dios, es el Verbo, es el ángel. El tú es un yo, un tú desdoblado.

Los dos primeros versos presentan unas igualdades que nos resumen el

${ }^{28}$ Vid. Valente, Variaciones..., Varbum asconditum, p. 202-203:

El deseo del místico postula un imposible, como todo verdadero deseo: llegar a ser el otro de quien no tiene otro, del non aliud, de aquél cuyo ser consiste en ser sin que nadie sea el otro de sí.

${ }^{29}$ Vid. Evangelio de San Mateo 16, 17 y San Juan 9, 10.

"CUADERNOS DE ESTUDIOS GALLEGOS", Tomo XL, Fascículo 105, Santiago 1992. 
cuerpo del poema:

COMO CRISTAL, como crustáceo o larva; cristal o larva o crustáceo, tienen en común que son embriones potencialidades, se clavan, se adhieren y pasan a constituir el otro cuerpo. Es así como el hombre deja que el dios lo habite.

Cristal, crustáceo o larva son embriones parasitarios: el cristal por su transparencia necesita la forma, el crustáceo necesita de su costra, la larva no es autónoma y se alimenta indirectamente de otro ser.

En la colección Al dios del lugar encontramos un poema, LOS SACERDOTES, que lleva esa misma anotación a su término. Este texto nos ofrece el panorama de una ofrenda, esto es, el ritual de presentar una víctima para el sacrificio. Se trata de un sacrificio buscado, incruento, inevitable también, como el ritual nocturno o, la ofrenda del poema. Es un sacrificio en soledad por medio del cual, la víctima se encuentra con el dios a solas ${ }^{30}$. La víctima es presentada solemnemente ante el altar, sin dolor, porque se encamina hacia una disolución largamente esperada y que le reportará el conocimiento y la posibilidad de consumirse, convirtiéndose en ceniza para luego incorporar una nueva materia. La víctima ofrece su cuerpo vivo para tomarla de nuevo. El dios propiciará el cuerpo resurrecto, cuando lentamente amanece el día:

\section{Lento el primer latido \\ o párpado del día resurrecto \\ empezó a oírse.}

La resurrección se lleva a cabo en soledad. Los Evangelios así nos lo confirman. Esa resurrección es equiparable al estado de escritura. En él, y en soledad, se lleva a cabo la desposesión del cuerpo, el hombre es instrumento del dios que habita en él y más tarde, el Verbo se encarna y encuentra así su forma. La totalidad de ese milagro se efectúa en el momento cumbre de la noche, en la cima de la madrugada. Y la luz se hace, y con ella se alcanza, sólo por un instante, el conocimiento puro, el poema. Y el poema es lenguaje y desde él ha de desentrañarse una experiencia de unión que el lenguaje por sí solo no puede contener.

${ }^{30}$ Vid. Valente, Verbum asconditum, en Variaciones..., p. 202 ss. 